\begin{tabular}{ll|l} 
Case Reports in & \multicolumn{2}{c}{ Case Rep Gastroenterol 2017;11:494-499 } \\
\cline { 2 - 3 } Gastroenterology & $\begin{array}{l}\text { DOI: 10.1159/000475751 } 2017 \text { The Author(s) } \\
\text { Publisned online: August 23, 2017 }\end{array}$ & $\begin{array}{l}\text { Published by S. Karger AG, Basel } \\
\text { www.karger.com/crg }\end{array}$ \\
\cline { 2 - 3 } & $\begin{array}{l}\text { This article is licensed under the Creative Commons Attribution-NonCommercial } 4.0 \\
\text { International License (CC BY-NC) (http://www.karger.com/Services/OpenAccessLicense). } \\
\text { Usage and distribution for commercial purposes requires written permission. }\end{array}$
\end{tabular}

\title{
Preoperative Diagnosis of Intestinal Endometriosis by Magnifying Colonoscopy and Target Biopsy
}

\author{
Jun Tomiguchi ${ }^{\mathrm{a}, \mathrm{b}}$ Hideaki Miyamoto ${ }^{\mathrm{a}}$ Kazutaka Ozono ${ }^{\mathrm{c}}$ \\ Ryosuke Gushima $^{a}$ Takashi Shono $^{a}$ Hideaki Naoe $^{a}$ Motohiko Tanaka ${ }^{a}$ \\ Hideo Baba ${ }^{d}$ Hidetaka Katabuchi $^{\mathrm{e}}$ Yutaka Sasaki $^{\mathrm{a}}$ \\ ${ }^{a}$ Department of Gastroenterology and Hepatology, Graduate School of Medical Sciences, \\ Kumamoto University, Kumamoto, Japan; ${ }^{b}$ Department of Gastroenterology and \\ Hepatology, National Hospital Organization Kumamoto Medical Center, \\ Kumamoto, Japan; 'Department of Diagnostic Pathology, Kumamoto University Hospital, \\ Kumamoto, Japan; ${ }^{d}$ Department of Gastroenterological Surgery, Graduate School of \\ Medical Sciences, Kumamoto University, Kumamoto, Japan; ${ }^{e}$ Department of Obstetrics \\ and Gynecology, Faculty of Life Sciences, Kumamoto University, Kumamoto, Japan
}

\section{Keywords}

Endometriosis · Magnifying endoscopy · Target biopsy

\begin{abstract}
Endometriosis can affect any portion of the gastrointestinal tract. A preoperative definitive diagnosis of intestinal endometriosis is difficult, because there is no characteristic endoscopic finding and the endoscopic biopsies usually sample insufficient endometrial tissue for pathologic diagnosis. To our knowledge, the magnifying endoscopic features of intestinal mucosal endometriosis have not been well documented. In this study, we report a case of intestinal endometriosis diagnosed preoperatively by magnifying image-enhanced colonoscopy and target biopsy. A 45-year-old woman was referred to our hospital with abdominal pain in the left lower quadrant. Colonoscopy showed a submucosal tumor-like lesion of approximately $30 \mathrm{~mm}$ in diameter exhibiting surface reddening and granular changes in the sigmoid colon. Magnifying endoscopy revealed sparsely distributed round pits in the granules. The mucosal biopsy specimen from the granule provided the diagnosis of intestinal endometriosis. Seg-
\end{abstract}


Tomiguchi et al.: Preoperative Diagnosis of Intestinal Endometriosis by Magnifying Colonoscopy and Target Biopsy

mental sigmoidectomy was performed, and pathological examination revealed that the surface colonic mucosa was partially replaced by endometrial tissue, which accounted for the granular change detected in the colonoscopy. It can be speculated that the round pit might reflect the endometrial glands surrounded by endometrial stroma. This case illustrated the characteristic finding and utility of magnifying endoscopy for mucosal intestinal endometriosis.

\section{Introduction}

Endometriosis, which is defined as the presence of endometrial glands and stroma outside of the uterus, affects approximately $20 \%$ of women of reproductive age [1]. These ectopic endometriosis can affect any portion of the gastrointestinal tract. Retrospective analyses have shown that bowel involvement was estimated to be present in 3.7 to $35 \%$ of the endometriosis cases [2]. Most patients with intestinal endometriosis have nonspecific mild symptoms, however, severe complications such as bowel obstruction might occur [3]. Although colonoscopy has been performed in many cases with intestinal endometriosis, the role of colonoscopy in the assessment of intestinal endometriosis is still controversial. It is difficult to make a definite diagnosis preoperatively, because there is no characteristic endoscopic finding and endoscopic biopsies usually sampled insufficient endometrial tissue for appropriate pathologic diagnosis [4]. To our knowledge, the magnifying endoscopic features of intestinal mucosal endometriosis have not been well documented.

Here, we report a case of intestinal endometriosis diagnosed through magnifying chromoendoscopy and target biopsy.

\section{Case Presentation}

A 45-year-old woman was referred to our hospital presenting abdominal pain in the left lower quadrant. Her earliest symptom was abdominal pain during the menstrual period. Gradually, the pain was getting severe and appeared any time regardless of the menstrual period.

A colonoscopy showed a 30-mm diameter submucosal tumor-like lesion exhibiting surface reddening and granular changes in the sigmoid colon (Fig. 1a). After dye spraying with $0.4 \%$ indigo carmine, depressed areas were clearly defined on the top of the granules (Fig. 1b). Magnification by chromoendoscopy using $0.05 \%$ crystal violet revealed sparsely distributed round pits in the depressed area (Fig. 1c).

The mucosal biopsy specimen from the granule contained glands composed of lowgrowing columnar epithelium in the lamina propria of the colon. Immunopositivity for the estrogen receptor in the gland and surrounding stroma provided the diagnosis of intestinal endometriosis (Fig. 2a, b).

Magnetic resonance imaging (MRI) showed a uterine myoma and chocolate cyst of the left ovary, which was adhering to the sigmoid colon (data not shown).

In this case, since the patient suffered from symptoms of bowel obstruction and had completed childbearing, segmental sigmoidectomy, total hysterectomy, left oophorosalpingectomy, and right salpingectomy were performed.

Histopathological examination of the resected sigmoid colon revealed that ectopic endometrial tissue infiltrated through the entire wall and exposed to the mucosa. The surface 
Tomiguchi et al.: Preoperative Diagnosis of Intestinal Endometriosis by Magnifying Colonoscopy and Target Biopsy

colonic mucosa was partially replaced by endometrial tissue, which accounted for the granular change detected in the colonoscopy, and a few endometrial glands opened into the bowel lumen (Fig. 3a, b). The round pits observed within the hypostructural area in Figure 1c seemed to be comparable to the endometrial glands surrounded by endometrial stroma.

\section{Discussion}

Among women with endometriosis, the reported prevalence of bowel involvement ranges from 3.7 to 35\% [2]. The rectum, including the rectosigmoid segment, is the most frequent site of bowel involvement with endometriosis, followed by the sigmoid colon, ileum, and cecum [5, 6]. Bloody stool during the menstrual cycle are highly suggestive of intestinal endometriosis, but the symptoms associated with intestinal endometriosis are mostly nonspecific: abdominal pain, diarrhea, and constipation. When endometriosis invades the bowel wall deeply, it might cause bowel obstruction [3].

Although colonoscopy is often performed in many cases with intestinal endometriosis, there is no disease-specific endoscopic finding. Previously reported colonoscopic findings of intestinal endometriosis included mucosal erythema, polyps or masses, eccentric wall thickening, and surface granularity and nodularity $[7,8]$. Furthermore, the magnifying endoscopic finding of intestinal endometriosis has not been well documented in the literature. The differential diagnosis should include inflammatory bowel diseases, diverticulitis, radiation colitis, ischemic colitis, malignancies of the gastrointestinal tract including metastatic tumor [4].

A definitive diagnosis is made by histological identification of endometrial tissue. However, the endoscopic biopsies usually obtained insufficient endometrial tissue because of the paucity of mucosal involvement. In a systematic review of women who underwent bowel resection for colorectal endometriosis, most women had involvement of the serosa and muscularis propria, and only $6 \%$ of cases had lesions that penetrated to the mucosa [9].

In this case, the colonoscopy showed a 30-mm diameter submucosal tumor-like lesion exhibiting surface reddening and granular changes in the sigmoid colon. Since the biopsy specimen from the granule contained only one endometrial gland, immunostaining for estrogen receptor was needed to confirm the definitive diagnosis. Pathologically, submucosal thickening seen on colonoscopy may be caused by deep invasion of endometriosis with subsequent fibrosis, and granular change may occur as the result of mucosal involvement of endometriosis. This was the reason why biopsy from the granule led to the definitive diagnosis. These results were consistent with the previous article reporting that the endoscopic biopsy of surface nodularity yielded a higher histologic diagnosis [8]. Furthermore, in this case, magnifying endoscopy using $0.05 \%$ crystal violet revealed sparsely distributed round pits in the granule. Pathological findings illustrated that the round pits observed in the top of granules were the indication for the opening of endometrial glands surrounded by endometrial stroma.

The therapeutic strategy is decided based on various factors such as symptom severity, patient preferences, medication side effects, treatment efficacy, contraceptive needs, costs, and availability [10]. The main purpose of intestinal endometriosis management is to relieve symptoms. Medical treatment, including nonsteroidal anti-inflammatory drugs and hormone therapy, is typically selected for patients with mild to moderate symptoms as initial treatment. Surgical treatment is selected for patients with persistent pain despite medical therapy, contraindications to or refusal of medical therapy, obstruction of the bowel tract, and needs for a tissue diagnosis of endometriosis. In this case, surgical resection was selected, 
Tomiguchi et al.: Preoperative Diagnosis of Intestinal Endometriosis by Magnifying Colonoscopy and Target Biopsy

because the patient had been suffering from symptoms of bowel obstruction and had completed childbearing.

In conclusion, we report a rare case of intestinal endometriosis preoperatively diagnosed through the use of magnifying endoscopy and target biopsy. This is the first case report that demonstrated the endometrial gland and stroma directly with magnifying endoscopy and contrasted pathological findings.

\section{Statement of Ethics}

This study was conducted according to the World Medical Association Declaration of Helsinki ethical principles for medical research involving human subjects. Written informed consent for participation was obtained from the patient.

\section{Disclosure Statement}

None of the authors has any financial conflicts of interest to declare.

\section{References}

1 Guo SW, Wang Y: Sources of heterogeneities in estimating the prevalence of endometriosis in infertile and previously fertile women. Fertil Steril 2006;86:1584-1595.

-2 Remorgida V, Ferrero S, Fulcheri E, Ragni N, Martin DC: Bowel endometriosis: presentation, diagnosis, and treatment. Obstet Gynecol Survey 2007;62:461-470.

3 Soumekh A, Nagler J: Gastrointestinal endometriosis causing subacute intestinal obstruction with gradual development of weight loss and misdiagnosed as irritable bowel syndrome. Case Rep Gastroenterol 2014;8:51-55.

4 Yantiss RK, Clement PB, Young RH: Endometriosis of the intestinal tract: a study of 44 cases of a disease that may cause diverse challenges in clinical and pathologic evaluation. Am J Surg Pathol 2001;25:445454.

5 Weed JC, Ray JE: Endometriosis of the bowel. Obstet Gynecol 1987;69:727-730.

6 Pereira RM, Zanatta A, Preti CD, de Paula FJ, da Motta EL, Serafini PC: Should the gynecologist perform laparoscopic bowel resection to treat endometriosis? Results over 7 years in 168 patients. J Minim Invasive Gynecol 2009;16:472-479.

7 Graham B, Mazier WP: Diagnosis and management of endometriosis of the colon and rectum. Dis Colon Rectum 1988;31:952-956.

-8 Kim KJ, Jung SS, Yang SK, Yoon SM, Yang DH, Ye BD, Byeon JS, Myung SJ, Kim JH: Colonoscopic findings and histologic diagnostic yield of colorectal endometriosis. J Clin Gastroenterol 2011;45:536-541. Meuleman C, Tomassetti C, D'Hoore A, Van Cleynenbreugel B, Penninckx F, Vergote I, D'Hooghe T: Surgical treatment of deeply infiltrating endometriosis with colorectal involvement. Hum Reprod Update 2011;17:311-326.

10 Dunselman GA, Vermeulen N, Becker C, Calhaz-Jorge C, D’Hooghe T, De Bie B, Heikinheimo O, Horne AW, Kiesel L, Nap A, Prentice A, Saridogan E, Soriano D, Nelen W; European Society of Human Reproduction and Embryology: ESHRE guideline: management of women with endometriosis. Hum Reprod 2014;29:400-412. 


\section{Case Reports in \\ Gastroenterology}

\begin{tabular}{l|l}
\hline Case Rep Gastroenterol 2017;11:494-499 \\
\hline DOI: 10.1159/000475751 & $\begin{array}{l}\text { @ 2017 The Author(s). Published by S. Karger AG, Basel } \\
\text { www.karger.com/crg }\end{array}$ \\
\hline
\end{tabular}

Tomiguchi et al.: Preoperative Diagnosis of Intestinal Endometriosis by Magnifying Colonoscopy and Target Biopsy
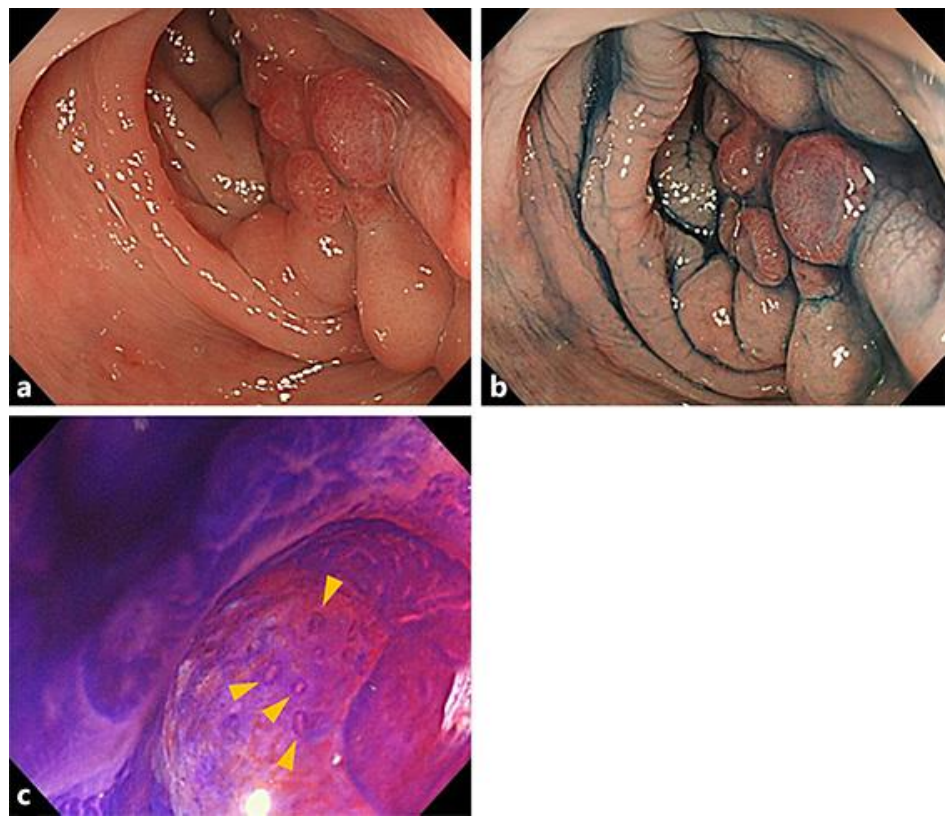

Fig. 1. a Conventional colonoscopy showed a submucosal tumor-like lesion of approximately $30 \mathrm{~mm}$ in diameter and exhibited surface reddening granular changes in the sigmoid colon. b Chromoendoscopy using indigo carmine dye spraying showed a depressed area on the top of the granules. c Magnifying colonoscopy with crystal violet staining showed the nonstructural area with scattered round pits (arrowheads) in the depressed area.
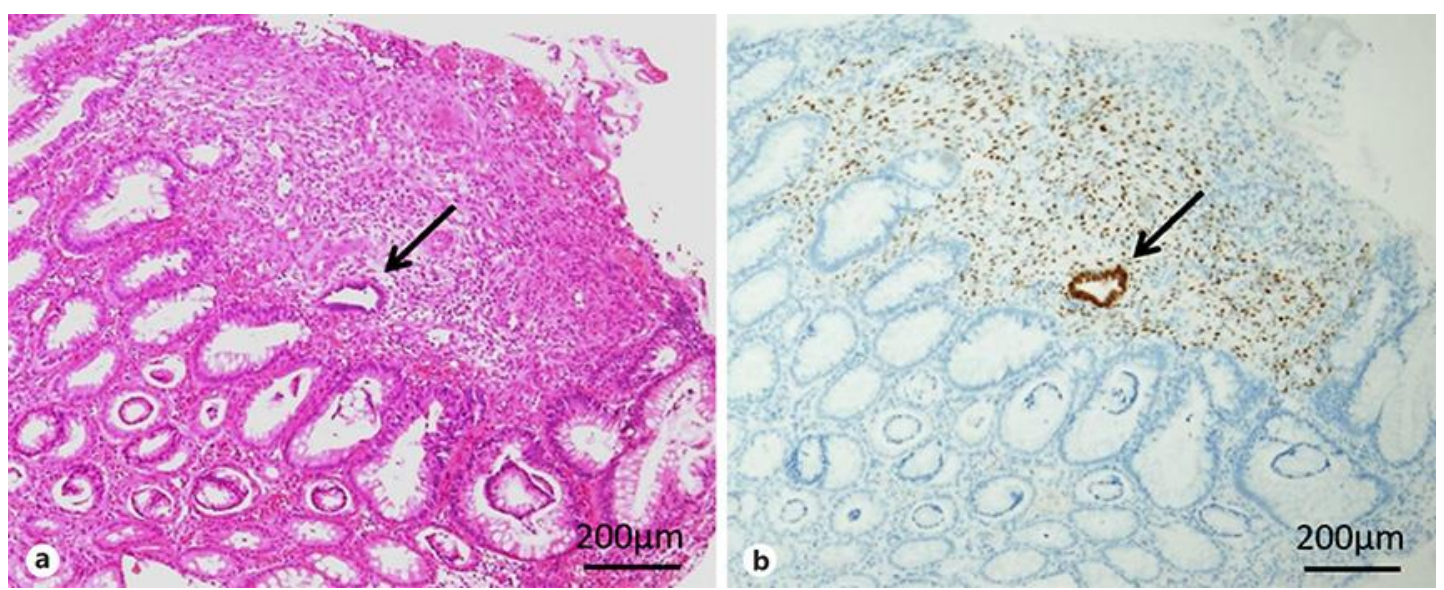

Fig. 2. Histopathological examination of the biopsy specimen. a In the lamina propria of the colon, only one ectopic endometrial gland with spindle and cellular stroma was observed (arrow). The gland was lined by cuboidal to low columnar epithelium. b Note the immunopositivity for the estrogen receptor in the ectopic endometrial gland (arrow) and its associated stroma. 

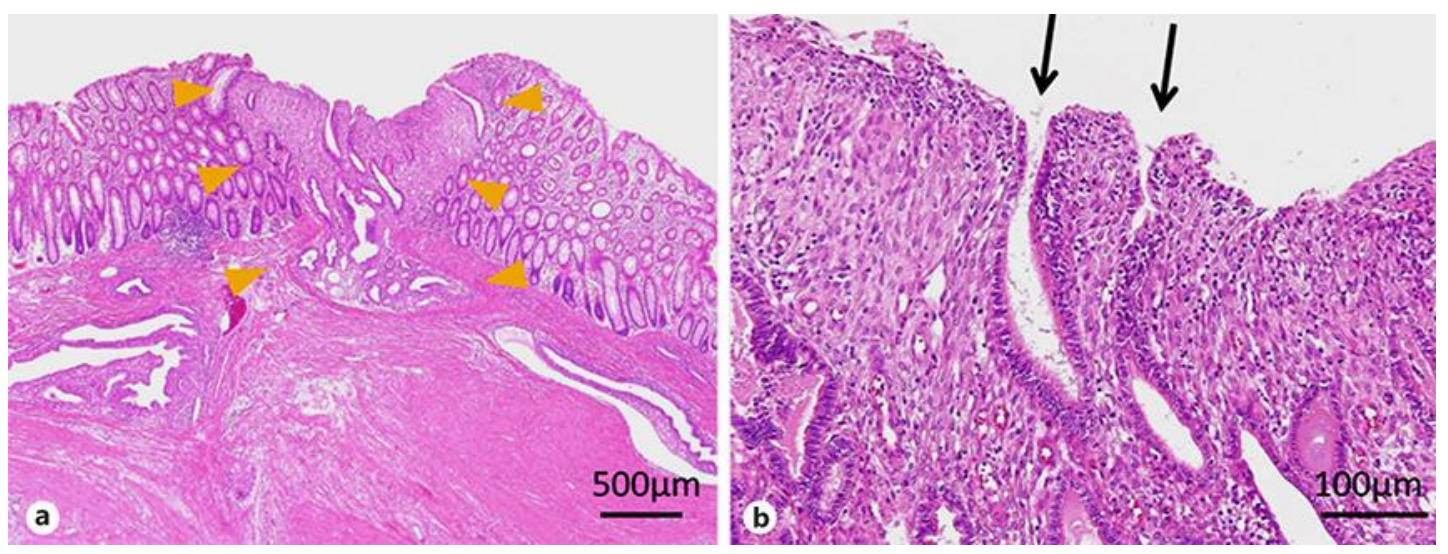

Fig. 3. Histopathological examination of the resected sigmoid colon. a Ectopic endometrial tissue infiltrated through the entire wall, and exposed to the mucosa (arrowheads). $\mathbf{b}$ The surface colonic mucosa was focally replaced by the endometrial tissue, which contributed to the granular change observed during colonoscopy. A few endometrial glands opened into the bowel lumen (arrows). 